\title{
Developmental Potential of Vitrified Holstein Cattle Embryos Fertilized In Vitro with Sex-Sorted Sperm
}

\author{
J. Xu, ${ }^{*}$ Z. Guo,† L. Su,‡ T. L. Nedambale, ${ }^{*}$ J. Zhang,§ J. Schenk,\# J. F. Moreno,\| A. Dinnyés,ף W. Ji,‡ \\ X. C. Tian,§ X. Yang,§ and F. Du*1 \\ *Evergen Biotechnologies, Inc., Storrs, CT 06269 \\ †Xinjiang Academy of Animal Science, the Key Laboratory of Animal Biotechnology of Ministry of Agriculture, Urumqi, Xinjiang 830000, China \\ ¥Kunming Institute of Zoology, Chinese Academy of Sciences, Kunming, Yunnan 650223, China \\ $\S$ Department of Animal Science/Center for Regenerative Biology, University of Connecticut, Storrs 06269 \\ \#XY Inc., Fort Collins, CO 80524 \\ |Sexing Technologies, Navasota, TX 77868 \\ १Department of Animal Biology, Agricultural Biotechnology Center, Godollo, Hungary
}

\begin{abstract}
In vitro fertilization (IVF) is a feasible way to utilize sex-sorted sperm to produce offspring of a predetermined sex in the livestock industry. The objective of the present study was to examine the effects of various factors on bovine IVF and to systematically improve the efficiency of IVF production using sex-sorted sperm. Both bulls and sorting contributed to the variability among differential development rates of embryos fertilized by sexed sperm. Increased sorting pressures (275.8 to $344.75 \mathrm{kPa}$ ) did not have a significant effect on the in vitro fertility of the sorted sperm; neither did an extended period of 9 to $14 \mathrm{~h}$ from semen collection to sorting. As few as 600 sorted sperm were used to fertilize an oocyte, resulting in blastocyst development of $33.2 \%$. Postwarming of vitrified sexed IVF embryos resulted in high morphological survival (96.3\%) and hatching (84.4\%) rates, similar to those fertilized by nonsexed sperm (93.1 and $80.6 \%$, respectively). A $40.9 \%$ pregnancy rate was established following the transfer of 3,627 vitrified, sexed embryos into synchronized recipients. This was not different from the rates with nonsexed IVF $(41.9 \%, \mathrm{n}=481)$, or in vivoproduced $(53.1 \%, \mathrm{n}=192)$ embryos. Of 458 calves born, $442(96.5 \%)$ were female and $99.6 \%$ appeared normal. These technologies (sperm sexing-IVF-vitrification-embryo transfer) provide farmers, as well as the livestock industry, with a valuable option for herd expansion and heifer replacement programs. In summary, calves were produced using embryos fertilized by sex-sorted sperm in vitro and cryopreserved by rapid cooling vitrification. Key words: sorted sperm, in vitro fertilization, vitrification, embryo transfer
\end{abstract}

Received October 2, 2005.

Accepted February 15, 2006.

${ }^{1}$ Corresponding author: fuliangd@evergen.com

\section{INTRODUCTION}

Separation of X- and Y-chromosome-bearing sperm by flow cytometry, and the subsequent application of sexsorted sperm to fertilize eggs in vivo or in vitro have resulted in offspring of predetermined sex in rabbits, sheep, pigs, horses, cattle, and humans, with accuracy as high as 95\% (Johnson, 2000). In vitro fertilization (IVF) is a feasible means to increase the fertilization efficiency of sex-sorted sperm (Wheeler et al., 2006). In cattle, approximately 5,000 unsorted sperm (Yang et al., 1993) and as few as 1,500 to 2,250 sexed sperm ( $\mathrm{Lu}$ and Seidel, 2004) are sufficient to fertilize a bovine oocyte in vitro, whereas 20 million unsorted sperm (Nadir et al., 1993) and as low as 1 million sorted and frozen sperm (Seidel, 1999) are normally used for one AI. Two pioneering studies by Cran et al. $(1993,1995)$ established pregnancies and produced calves of predictable sex from fresh and frozen IVF embryos fertilized with sorted sperm. Little progress on sexed IVF embryo transfer in cattle has been reported since then. Various problems associated with obtaining satisfactory embryo transfer (ET) include the difficulty in obtaining sufficient numbers of sorted sperm with good motility (Schenk et al., 1999), less than optimal IVF and culture systems (Lu and Seidel, 2004; Wilson et al., 2005, 2006), and unsuccessful cryopreservation (Sommerfeld and Niemann, 1999). A few in vitro studies have suggested that IVF efficiency using sorted sperm was affected by sires (Lu and Seidel, 2004 ), the speed and pressure of the sorting process (Zhang et al., 2003), and transportation of semen (transport duration and temperature) from the bull studs to a sorting facility (Cran et al., 1995). The blastocyst development rate was significantly lower with sorted sperm than with unsorted control sperm (Lu et al., 1999; Wilson et al., 2005, 2006).

The objective of the present study was to systematically improve the efficiency of bovine IVF production using sex-sorted sperm. Effects of sires, time between 
semen collection and sorting, and sperm-sorting pressure on in vitro fertilization rates, and embryonic developmental competence were studied. We utilized a newly developed liquid nitrogen surface vitrification (LNSV) method (Du et al., 2004, 2006) with presumptive female IVF Holstein embryos and examined LNSV on subsequent in vitro survival rates of embryos and their in vivo development to birth.

\section{MATERIALS AND METHODS}

All chemicals were purchased from Sigma Aldrich (St. Louis, MO) unless otherwise noted. All embryos were cultured at $39^{\circ} \mathrm{C}$ in $5 \% \mathrm{CO}_{2}$ and humidified air (unless otherwise specified).

\section{Preparation of Sorted X-Chromosome-Bearing Holstein Sperm}

Sorted X-bearing sperm from 9 Holstein bulls (A to I) were produced by flow cytometry using XY sorting methods as described earlier (Schenk et al., 1999) in the sorting facilities at XY Inc. (Fort Collins, CO) and Sexing Technologies Inc. (Navasota, TX). Bulls were selected on their genetic merit and availability, without evaluation of their fertility in vitro. Fresh ejaculates were maintained at $19 \pm 1^{\circ} \mathrm{C}$ for 9 or $14 \mathrm{~h}$ before sorting. A total of $200 \times 10^{6}$ sperm were aliquoted into $1.0 \mathrm{~mL}$ of HEPESBSA extender containing $112 \mu M$ Hoechst 33342 and stained for $45 \mathrm{~min}$ at $34.5^{\circ} \mathrm{C}$. One microliter of $5 \%$ food coloring (FD\&C \#40; Sensient Colors, Norfolk, UK) was mixed gently into semen samples for 5 min to stain damaged sperm. Sperm samples were filtered through a 50- $\mu \mathrm{m}$ nylon mesh to remove any debris or clumped sperm before sorting. The variables for flow cytometry were set as follows: sheath pressure at 275.8 to 344.75 $\mathrm{kPa}$, according to the experimental design, $70-\mu \mathrm{m}$ orifice tip, sort deflection of 1 drop, $150 \mathrm{~mW}$ laser power at distinguishing wavelengths of 351 and $364 \mathrm{~nm}$, and average flow rates from 25,000 to $30,000 \mathrm{sperm} / \mathrm{s}$. The $\mathrm{X}$ - and Y-chromosome-bearing sperm were sorted into different tubes based on their 3.8\% inherent difference in DNA content (van Munster et al., 1999). Approximately $12 \times$ $10^{6}$ sorted sperm were collected into $2 \mathrm{~mL}$ of $20 \%$ egg yolk-Tris-A (200 $\mathrm{m} M$ Tris, $65 \mathrm{~m} M$ citric acid monohydrate, $56 \mathrm{~m} M$ fructose), together with $10 \mathrm{~mL}$ of sorting medium, and then cooled to $5^{\circ} \mathrm{C}$ over $90 \mathrm{~min}$. Sorted sperm then received an equal volume of Tris containing $12 \%$ glycerol in 2 equal fractions, $15 \mathrm{~min}$ apart. The tubes were centrifuged at $850 \times g$ for $20 \mathrm{~min}$ at $5^{\circ} \mathrm{C}$, the supernatant removed, like pellets pooled, and the sperm concentration adjusted to $10 \times 10^{6} \mathrm{sperm} / \mathrm{mL}$ with $20 \%$ egg yolk Tris containing 6\% glycerol. Extended sperm then were packaged in $0.25-\mathrm{mL}$ straws $\left(2.0 \times 10^{6}\right.$ sorted sperm), frozen on racks in a liquid nitrogen vapor phase $\left(-160^{\circ} \mathrm{C}\right)$, and stored in liquid nitrogen. The purity of sorted sperm was $90 \pm 3 \%$ based on re-sort analysis.

\section{Collection and Maturation of Bovine Oocytes In Vitro}

Holstein cattle were selected and separated from beef and other dairy breeds at the slaughterhouse $1 \mathrm{~d}$ before slaughtering. Cumulus-oocyte-complexes (COC) used in this study were collected from ovaries of Holstein cows (Yang et al., 1993). The COC with at least 4 intact layers of cumulus cells were selected and washed 3 times in Dulbecco's PBS (Invitrogen, Grand Island, NY) supplemented with $0.1 \%$ polyvinyl alcohol. Oocytes were matured in groups of 25, in 75- $\mu \mathrm{L}$ drops of Medium 199 (Invitrogen) containing Earle's salts, L-glutamine, $2.2 \mathrm{~g} /$ $\mathrm{L}$ sodium bicarbonate, and $25 \mathrm{~m} M$ HEPES, supplemented with $7.5 \%$ (vol/vol) fetal bovine serum (FBS; Hyclone, Logan, UT) and $0.5 \mu \mathrm{g} / \mathrm{mL}$ ovine FSH (National Institute of Diabetes and Digestive and Kidney Disease, Los Angeles, CA), $5.0 \mu \mathrm{g} / \mathrm{mL}$ ovine LH (NIDDK), and $1.0 \mu \mathrm{g} / \mathrm{mL}$ estradiol $17-\beta$. The maturation medium was covered with mineral oil, and COC were cultured for 24 h. The COC with well-expanded cumulus layers at the end of maturation were selected for IVF with sorted Xbearing sperm according to the experimental design.

\section{In Vitro Fertilization with Sorted X-Bearing Sperm}

Sorted frozen Holstein X-bearing sperm were used for IVF in Brackett and Oliphant (BO) medium (Brackett et al., 1982). Briefly, straws containing semen were thawed for $10 \mathrm{~s}$ in a $37^{\circ} \mathrm{C}$ water bath after $10 \mathrm{~s}$ of gentle shaking in air at room temperature. Spermatozoa were washed in $8 \mathrm{~mL}$ of $\mathrm{BO}$ medium with $3 \mathrm{mg} / \mathrm{mL}$ of BSA and $10 \mathrm{~m} M$ caffeine. The washed sperm pellet was resuspended in BO washing solution at various doses according to the experimental design. Matured COC were rinsed in $\mathrm{BO}$ medium containing $6 \mathrm{mg} / \mathrm{mL}$ BSA and 10 $\mu \mathrm{g} / \mathrm{mL}$ heparin, and 25 allocated per droplet. An appropriate volume of sperm suspension, with a final sperm concentration of 0.15 or $0.3 \times 10^{6} / \mathrm{mL}$, was added to each oocyte-containing fertilization droplet according to experimental design. Oocytes and washed sperm were incubated for $6 \mathrm{~h}$ in the volume specified for each experiment. Unsorted frozen sperm from the same 4 Holstein bulls were used for the nonsexed sperm fertilization. The procedures for unsorted sperm IVF were the same as described above, except that the final sperm concentration was $0.6 \times 10^{6} / \mathrm{mL}$.

\section{In Vitro Culture of Sexed Embryos}

Embryos were cultured in CR1aa medium (Rosenkrans et al., 1993). After IVF, cumulus cells were 
stripped from presumptive zygotes and washed in CR1aa medium. Presumptive zygotes were randomly allocated to CR1aa culture containing $6 \mathrm{mg} / \mathrm{mL}$ of BSA under $5 \%$ $\mathrm{CO}_{2}, 5 \% \mathrm{O}_{2}$, and $90 \% \mathrm{~N}_{2}$, and incubated for $2 \mathrm{~d}$ before they were transferred into cumulus cell coculture containing CR1aa medium with $10 \%$ (vol/vol) FBS and cultured for a further $5 \mathrm{~d}$. Cleavage status of embryos was evaluated on d 2 (2 to 8 cells), 5 (morula), and 7 (blastocyst) of culture. Embryos were graded according to International Embryo Transfer Society standards (Robertson and Nelson, 1998). Expanding blastocysts with a compact inner cell mass were graded as $\mathrm{C} 1$, and selected for cryopreservation. The total number of blastocysts recorded was the sum of grade C1 and C2 embryos (Robertson and Nelson, 1998). The cell number of the C1 grade blastocysts was evaluated by fluorescence microscopy following staining with $10 \mu \mathrm{g} / \mathrm{mL}$ of Hoechst 33342 .

\section{PCR Confirmation of Sexed Female Embryos}

Samples of the IVF embryos were digested with 20 $\mu \mathrm{L}$ of K-buffer containing $0.1 \mu \mathrm{g} / \mu \mathrm{L}$ proteinase $\mathrm{K}$ (Invitrogen) at $56^{\circ} \mathrm{C}$ for $45 \mathrm{~min}$, and then held at 95 to $100^{\circ} \mathrm{C}$ for $10 \mathrm{~min}$ to inactivate proteinase $\mathrm{K}$. A multiplex amplification of bovine specific autosome and Y-chromosome fragments was performed by one round of PCR (Tominaga and Hamada, 2004). A bovine-specific primer pair was designed to amplify a fragment of $219 \mathrm{bp}$ from a bovine 1.715 satellite DNA as follows: forward: $5^{\prime}$-TGA GGC ATG GAA CTC CGC TT-3'; reverse: 5'-GGT GGT TCC ACA TTC CGT AGG AC-3'. The Y-chromosome fragment (131 bp) was amplified using male-specific primers (forward: 5'-GAT TGT TGA TCC CAC AGA AGG CAA TC-3'; reverse: 5'-GAA CTT TCA AGC AGC TGA GGC ATT TA-3'). One microliter of embryo lysate was used for PCR amplification in a total volume of $25 \mu \mathrm{L}$ containing $10 \mathrm{~m} M$ Tris- $\mathrm{HCl}$ (pH 8.3), $50 \mathrm{mM} \mathrm{KCl,} 2 \mathrm{mM}$ $\mathrm{MgCl}_{2}, 0.2 \mathrm{~m} M$ dNTP (DNTP100A), $0.4 \mu M$ oligonucleotide primers, and 0.5 unit of REDTaq DNA polymerase (Invitrogen). The PCR was initiated with an initial cycle of $95^{\circ} \mathrm{C}$ for $2 \mathrm{~min}$ followed by 30 cycles of $95^{\circ} \mathrm{C}$ for $30 \mathrm{~s}$, primer annealing at $64^{\circ} \mathrm{C}$ for $30 \mathrm{~s}$, primer extension at $72^{\circ} \mathrm{C}$ for $30 \mathrm{~s}$, and a final hold at $72^{\circ} \mathrm{C}$ for $10 \mathrm{~min}$. Ten microliters of PCR products were analyzed on a $2 \%$ agarose gel. One band (219 bp) indicated a female embryo, and 2 bands (219 and $131 \mathrm{bp}$ ) indicated a male embryo.

\section{Cryopreservation of Preselected Female Embryos}

Embryos were cryopreserved by LNSV (Vitrification and Warming Kit, Evergen Biotechnologies, Inc., Storrs, CT; Du et al., 2004). Briefly, bovine blastocysts were serially incubated in Rinse, Base, and Hold medium for 3 min before vitrification of 4 to 5 embryos in a $2-\mu \mathrm{L}$ vitrification medium microdroplet, by direct placement onto a thin layer of liquid nitrogen on the solid surface of a metal plate. A group of 30 to 50 vitrified embryos were then transferred into a small freezing vial with a cold fine-tipped forceps, sealed, and stored in the vapor phase of liquid nitrogen $\left(-160^{\circ} \mathrm{C}\right)$.

\section{In Vitro Evaluation of Vitrified Female Holstein Embryos}

To test the viability of vitrified embryos, frozen embryos were sequentially warmed, rehydrated, and washed in Warm, Rehydrate, and Base media (Evergen Biotechnologies Inc.) at $39^{\circ} \mathrm{C}$ for 5 min each. Embryo survival was evaluated morphologically under stereomicroscopy when embryos were still alive before fixation. Frozen-thawed embryos were cultured in vitro for $3 \mathrm{~d}$ under cumulus coculture containing 10\% FBS M199 culture medium, and the survival or hatching rates were recorded at $0,24,48$, and $72 \mathrm{~h}$. At $72 \mathrm{~h}$ of culture, 25 hatched blastocysts from each treatment were stained with Hoechst 33342 and analyzed under fluorescence microscopy for cell counts.

\section{Embryo Transfer of Female Blastocysts}

Vitrified presumptive female bovine IVF embryos were transferred into recipients to examine their developmental potential in vivo. Recipient cattle breeds consisted of Chinese Native Yellow Cattle and Holstein cattle on several Chinese farms. Recipients were chosen according to criteria that included: age, health status, breeding history, size and weight, as well as the farm's nutritional management. Recipients were synchronized by a regimen of 2 injections of prostaglandin $\mathrm{F}_{2 \alpha}$ (Lutalyse, Upjohn Co., Kalamazoo, MI; 25 mg/injection, i.m.) at an interval of $11 \mathrm{~d}$. Corpus luteum (CL) regression and estrus usually occurred approximately 48 to $72 \mathrm{~h}$ later. The onset of estrus of recipients (d 0) was monitored closely by observing animals that stood when mounted. On d 7 following estrus, recipients were selected by palpation per rectum to verify the presence and the size of the CL. The vitrified microdroplets containing embryos were thawed through a series of steps described above. Blastocysts (1/straw) were loaded into $0.25-\mathrm{mL}$ French straws containing ViGro Holding Plus (AB Technology, Pullman, WA). Straws were maintained at $39^{\circ} \mathrm{C}$ in a portable incubator for transportation to the farms. A single embryo was deposited nonsurgically into the uterine horn ipsilateral to the ovary with the CL. Pregnancy was determined by palpation per rectum on $\mathrm{d} 70$ after transfer. 


\section{Statistical Analyses}

The proportions of presumptive zygotes from various treatments reaching cleavage and developing to morula or blastocyst stage within each experiment as well as embryo transfer data were determined and transformed by an arc sine transformation. The transformed data then were analyzed by ANOVA (GLM, SPSS 11.0, Chicago, IL). A 2-way ANOVA with main effects and an interaction was used to analyze the $2 \times 2$ experimental designed data in experiments 2 and 3 . The mean number of nuclei for postwarmed/vitrified embryos was compared by 1 -way ANOVA. A $P$-value $<0.05$ was considered significant.

\section{Experimental Designs}

Experiment 1: Sorting Influence and Bull Effect on Sexed IVF. The effects of bull or sorting on fertility were determined using 4 bulls (A to D) and compared with fertility of unsorted sperm from the same bulls. The developmental competence of embryos fertilized by sorted sperm from 9 different bulls (A to I) was examined to test the sire's competence for effective sexed IVF. Matured oocytes were randomly assigned to IVF by sorted sperm from the 9 different bulls in a standard $100-\mu \mathrm{L}$ fertilization droplet. The final concentration was $0.3 \times$ $10^{6} \mathrm{sperm} / \mathrm{mL}$ (1,200 sperm per oocyte).

Experiment 2: Minimal Concentration and Number of X-Bearing Sperm for Effective Embryo Development In Vitro. This experiment was designed to determine whether the concentration of sperm could be further decreased for effective fertilization. A $2 \times 2$ factorial design was carried out as follows: a fertilization medium volume of $100 \mathrm{vs} .50 \mu \mathrm{L}$ and final concentrations of sorted X-bearing sperm of $0.3 \times 10^{6}$ vs. $0.15 \times 10^{6}$ sperm $/ \mathrm{mL}$ from bull A.

Experiment 3: Effect of Sorting Pressure and Length of Storage Time Before Flow Cytometric Sorting on IVF. This experiment was designed $(2 \times 2$ factorial) to determine: 1 ) whether IVF was affected by sorting pressure (50 psi, high-speed sorting vs. $40 \mathrm{psi}$, low-speed sorting), and 2) whether longer periods during the transport of ejaculates before sorting (9 vs. $14 \mathrm{~h}$ at $15^{\circ} \mathrm{C}$ ) would adversely affect sperm fertility or embryo development. Long periods before sorting would enable the use of ejaculates from elite bulls that are distant from the few sorting facilities in the nation.

Experiment 4: In Vitro Evaluation and Term Development of Vitrified Female Embryos. This experiment evaluated the in vitro and in vivo developmental competence of vitrified sexed embryos. Embryos were cryopreserved by LNSV, which has proven effective with IVF embryos produced by unsorted sperm (Du et al., 2004). After thawing, the embryos were either cultured in vitro for $3 \mathrm{~d}$ or transferred to synchronized recipient animals. Survival rates, hatching rates, and cell counts were recorded for in vitro-produced embryos. The PCR was conducted to confirm the sex of IVF embryos. For ET trials, the vitrified sexed embryos were transferred immediately after warming. The IVF embryos fertilized by unsorted sperm were used as controls for both in vitro and in vivo studies. Commercially purchased in vivoproduced embryos, frozen by conventional slow freezing, were used as controls for the ET trials.

\section{RESULTS}

\section{Experiment 1}

There was significant variation among the developmental rates of embryos fertilized by unsorted sperm from bulls A, B, C, and D (Table 1). Similar blastocyst rates of IVF embryos were found between sorted and unsorted sperm from bulls $\mathrm{A}, \mathrm{B}$, and $\mathrm{D}(P>0.05)$, but the blastocyst rate was higher for unsorted than for sexed sperm from bull C ( 20.7 vs. $0.7 \% ; P<0.05$; Table 1$)$.

We further examined the development of embryos produced by sorted sperm from 9 different bulls (A to I). The embryos resulting from sperm from bulls A, E, and $\mathrm{F}$ had higher $(P<0.05)$ rates of blastocyst $(22.1,30.4$, and $20.1 \%$, respectively) development compared with those of the other 6 bulls (0.7 to 2.1\%; Figure 1). The sorted sperm from bulls A, E, and F ( $3 / 9$ bulls) was highly fertile, and resulting blastocyst development rates were comparable to those of the unsorted sperm of a good IVF bull (bull A, $P>0.05$ ). Semen from bull A was selected for use in the remaining in vitro experiments.

\section{Experiment 2}

A $2 \times 2$ factorial design (fertilization with a sperm concentration at $0.3 \times 10^{6}$ vs. $0.15 \times 10^{6} / \mathrm{mL}$ and a fertilization drop size of 50 vs. $100 \mu \mathrm{L}$; treatments 1 to 4) was conducted to examine the dosage effect of X-sperm fertilization in vitro (Table 2). A higher sperm concentration $\left(0.3 \times 10^{6} / \mathrm{mL}\right.$, treatments 1 and 3$)$ for IVF yielded higher $(P<0.05)$ blastocyst development rates $(31.0$ to $33.2 \%$ ) than those (11.3 to $12.9 \%$ ) using a lower sperm concentration $\left(0.15 \times 10^{6} / \mathrm{mL}\right.$, treatments 2 and 4$)$, regardless of the size of the fertilization droplet (50 vs. $100 \mu \mathrm{L}$ ). Size of the fertilization droplet did not affect the developmental potential in vitro $(P>0.05)$. The most effective dosage for supporting satisfactory development to the blastocyst stage was 600 sperm per oocyte, at a sperm concentration of $0.3 \times 10^{6} / \mathrm{mL}$ (treatment 1 , $31.0 \%)$. Compared with our standard fertilization method (1,200 sperm/oocyte, treatment $3,33.2 \%)$, treatment 1 (600 sperm/oocyte) provided the same embryo yield with half the number of sperm. 
Table 1. Bull effect on the development of oocytes fertilized by presexed Holstein sperm

\begin{tabular}{|c|c|c|c|c|c|}
\hline \multirow[b]{2}{*}{ Bull } & \multirow[b]{2}{*}{ Treatment $^{1}$} & \multirow{2}{*}{$\begin{array}{l}\text { Total } \\
\text { oocytes } \\
\text { (n) }\end{array}$} & \multicolumn{3}{|c|}{ Embryo development (mean \pm SEM) } \\
\hline & & & Cleavage, $\%$ & Morula, \% & Blastocyst, $\%$ \\
\hline \multirow[t]{2}{*}{ A } & Sorted & 727 & $69.1 \pm 7.4^{\mathrm{a}}$ & $46.8 \pm 7.3^{\mathrm{a}}$ & $22.1 \pm 2.6^{\mathrm{a}}$ \\
\hline & Unsorted & 522 & $60.5 \pm 5.1^{\mathrm{ab}}$ & $32.4 \pm 3.8^{\mathrm{b}}$ & $26.5 \pm 4.3^{\mathrm{a}}$ \\
\hline \multirow[t]{2}{*}{ B } & Sorted & 640 & $19.6 \pm 3.9^{c}$ & $3.1 \pm 0.6^{\mathrm{c}}$ & $2.0 \pm 0.5^{\mathrm{b}}$ \\
\hline & Unsorted & 468 & $29.6 \pm 9.3^{\mathrm{cd}}$ & $8.5 \pm 3.9^{\mathrm{c}}$ & $7.2 \pm 3.4^{\mathrm{b}}$ \\
\hline \multirow[t]{2}{*}{$\mathrm{C}$} & Sorted & 720 & $32.1 \pm 1.3^{\text {ce }}$ & $1.4 \pm 0.2^{\mathrm{c}}$ & $0.7 \pm 0.2^{\mathrm{b}}$ \\
\hline & Unsorted & 518 & $78.1 \pm 5.9^{\mathrm{a}}$ & $29.0 \pm 6.5^{\mathrm{b}}$ & $20.7 \pm 3.5^{\mathrm{a}}$ \\
\hline \multirow[t]{2}{*}{$\mathrm{D}$} & Sorted & 600 & $46.4 \pm 5.4^{\mathrm{bdef}}$ & $5.0 \pm 0.1^{\mathrm{c}}$ & $1.2 \pm 0.4^{\mathrm{b}}$ \\
\hline & Unsorted & 524 & $37.7 \pm 5.4^{\mathrm{cf}}$ & $11.7 \pm 1.7^{\mathrm{c}}$ & $7.3 \pm 2.5^{\mathrm{b}}$ \\
\hline
\end{tabular}

\footnotetext{
${ }^{a-f}$ Values with different superscripts within columns are significantly different $(P<0.05)$. Embryo development to cleavage ( 2 to 8 cell), morulae, and blastocyst was evaluated on d 2, 5, and 7 post in vitro fertilization, respectively, according to the standards of the International Embryo Transfer Society.

${ }^{1}$ There were 4 replicates for each bull.
}

\section{Experiment 3}

To examine the effect of sperm sorting pressure and the interval between collection and sorting of sperm on IVF, fresh ejaculates from bull A were subjected to the following treatments: 1 ) sorted at $275.8 \mathrm{kPa}, 9 \mathrm{~h}$ postejaculation; 2) sorted at $275.8 \mathrm{kPa}, 14 \mathrm{~h}$ postejaculation; 3) sorted at $344.75 \mathrm{kPa}, 9 \mathrm{~h}$ postejaculation, and 4) sorted at $344.75 \mathrm{kPa}, 14 \mathrm{~h}$ postejaculation. The final fertilization concentration of sorted sperm used was $0.3 \times 10^{6} / \mathrm{mL}$, and the sperm dose was 600 per oocyte as determined in experiment 2 . There was no difference in cleavage or embryonic development to the blastocyst stage among these 4 treatments $(P>0.05$, Table 3$)$. Neither the increased sorting pressure ( 344.75 vs. $275.8 \mathrm{kPa}$ ), nor the extended period ( 14 vs. $9 \mathrm{~h}$ ) postejaculation resulted in adverse effects on blastocyst development rates (Table $3)$.

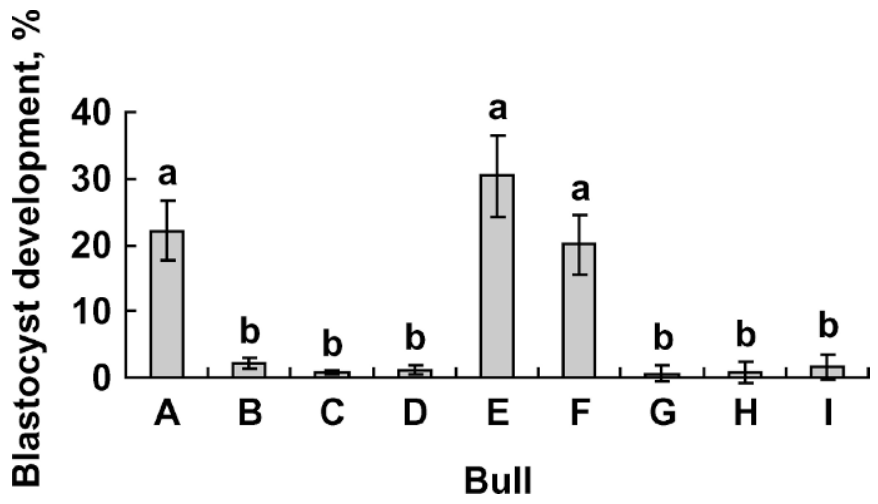

Figure 1. Differential bull effect on in vitro development (embryonic development to blastocyst stage; mean \pm SD) of Holstein oocytes fertilized by sorted sperm. Sorted X-bearing sperm from 9 bulls (A to I) were used to examine their fertility via in vitro fertilization (IVF) and culture. Bulls A, E, and F had similar developmental potential during sexed IVF $(P>0.05)$ and significantly higher fertility $(P$ $<0.05$ ) than the other bulls.

\section{Experiment 4}

Vitrified embryos produced by sorted $(\mathrm{n}=164)$ and unsorted ( $\mathrm{n}=149$, Table 4) sperm from bull A were thawed to examine their survivability and developmental potential in vitro. Vitrified, sexed IVF blastocysts shrunk morphologically and formed a compact cell mass (Figure 2A) immediately after warming; however, they recovered well to expanding blastocysts, morphologically indistinguishable from embryos before vitrification (Figure 2B). No difference was found in the postthawing viability of sexed (96.3\%) and control (91.8\%) blastocysts (Table 4$)$. Similar hatching rates ( 84.4 vs. $80.6 \%$ ) were found in both thawed sexed, and control embryos after $72 \mathrm{~h}$ culture postthawing. Twenty-five hatched embryos from each vitrified and warmed sexed and nonsexed group were selected for cell counting and nuclear evaluation. The mean cell number of the vitrified and sexed IVF blastocysts was $538 \pm 35$ (Table 4), similar to those fertilized with nonsexed sperm ( $515 \pm 33, P>0.05)$.

One hundred eighteen blastocysts derived from unsorted sperm from bull A and 148 blastocysts derived by sorted sperm from bull A were subjected to PCR sexing. From IVF with unsorted sperm, 54.2\% of embryos were female, whereas $95.9 \%$ of embryos from IVF with Xsorted sperm were female (Figure 3 ). This result confirmed the accuracy of the sex sorting of sperm.

Embryo transfer was performed to evaluate the in vivo developmental potential of the sexed, vitrified IVF embryos (Table 4). A total of 3,627 sexed embryos (2,060 by bull A; 1,567 by bull $\mathrm{E}$ ) were transferred with $1 \mathrm{em}$ bryo per recipient. Traditional IVF embryos $(\mathrm{n}=481)$ produced by unsorted sperm and conventional in vivo embryos $(n=192)$ served as nonsexed control groups. Sexed IVF embryos yielded a pregnancy rate of $40.9 \%$ (Table 4), similar to that of nonsexed IVF embryos (41.9\%, $P>0.05)$. There was no difference between the pregnancy rates of embryos fertilized by bull $\mathrm{A}$ and bull 
Table 2. The minimum concentration and number of X-bearing sperm for effective in vitro fertilization (IVF) and embryonic development in vitro ${ }^{1}$

\begin{tabular}{|c|c|c|c|c|c|c|c|}
\hline Treatment $^{2}$ & $\begin{array}{l}\text { Sperm } \\
\text { concentration } \\
\left(10^{6} / \mathrm{mL}\right)^{2}\end{array}$ & $\begin{array}{l}\text { Droplet } \\
\text { size }(\mu \mathrm{L})\end{array}$ & $\begin{array}{l}\text { Ratio of } \\
\text { sperm/oocyte }^{3}\end{array}$ & $\begin{array}{l}\text { Oocytes } \\
\text { (n) }\end{array}$ & \multicolumn{3}{|c|}{ Embryo development (mean \pm SEM) } \\
\hline 1 & 0.3 & 50 & 600 & 285 & $72.3 \pm 1.2^{\mathrm{a}}$ & $39.4 \pm 4.5^{\mathrm{a}}$ & $31.0 \pm 2.9^{\mathrm{a}}$ \\
\hline 3 & 0.3 & 100 & 1,200 & 233 & $80.8 \pm 5.6^{\mathrm{a}}$ & $45.5 \pm 3.1^{\mathrm{a}}$ & $33.2 \pm 2.9^{\mathrm{a}}$ \\
\hline 4 & 0.15 & 100 & 600 & 250 & $39.1 \pm 2.7^{b}$ & $14.2 \pm 2.4^{\mathrm{b}}$ & $12.9 \pm 2.7^{\mathrm{b}}$ \\
\hline
\end{tabular}

${ }^{a, b}$ Values with different superscripts within columns are significantly different $(P<0.05)$.

${ }^{1}$ There were 3 replicates per treatment. Embryo development to cleavage ( 2 to 8 cell), morulae, and blastocyst was evaluated on $\mathrm{d} 2,5$, and 7 post-IVF, respectively, according to the standard of the International Embryo Transfer Society.

${ }^{2}$ Sperm concentration indicates the final concentration of sorted X-bearing sperm used in the droplets according to experimental design. A group of 25 oocytes was arranged into each droplet with a volume of 50 or $100 \mu \mathrm{L}$. Depending on the sperm final concentration in each fertilizing droplet, the ratio of sperm to per oocyte was calculated.

E (39.4 and 43.0\%, respectively, $P>0.05$ ). The pregnancy rates with sexed as well as unsexed IVF embryos were not different from control in vivo embryos $(53.1 \%, \mathrm{n}=$ 192).

Live Holstein calves were produced from the sexed IVF, vitrified, transferred embryos. Presently, the majority of these pregnancies are ongoing. To date, 458 live calves have been born, of which 442 are female (96.5\%). Most calves appeared normal and healthy (Figure 2C). In these 458 animals, 2 had physical defects and 1 died within $1 \mathrm{~h}$ of birth. From the data collected, 39 abortions were observed from 711 pregnancies at $\mathrm{d} 70(5.5 \%)$. This was not different from that of nonsexed IVF $(5.4 \%, \mathrm{n}=$ $481)$ or in vivo-produced $(4.8 \%, \mathrm{n}=192)$ embryos.

\section{DISCUSSION}

In the present study, we achieved $33.2 \%$ blastocyst development using X-sorted sperm from a selected bull, which was indistinguishable from results using unsorted control sperm for IVF. Embryonic development to the blastocyst stage was not delayed. Sexed and nonsexed embryos were indistinguishable morphologically with similar cell numbers, similar to the findings of Beyhan et al. (1999). In vitro fertilization is a feasible application for utilizing sorted sperm, based on current sexing technology (Lu et al., 1999; Lu and Seidel, 2004; Wilson et al., 2005). Previous studies with sexed IVF embryos (Cran et al., 1993, 1995; Wilson et al., 2006) indicated that embryos resulting from sexed sperm IVF had an inferior (12 to 27\%), and sometimes delayed preimplantation development to blastocyst. The unaffected developmental dynamics of sexed embryos provided evidence that acceptable results can be attained with sorted sperm in an IVF situation. The possible reasons for our improvement include the choice of bull, and improvements to the sorting, fertilization, and culture processes. Brackett and Oliphant fertilization medium, which requires a relatively short sperm-oocyte incubation $(6 \mathrm{~h})$ period, was used in our study. In contrast, prolonged sperm-oocyte incubation (18 to $24 \mathrm{~h}$ ) and a different fertilization system were used (HEPES-chemical defined medium fertilization) by others (Lu and Seidel, 2004).

In the present study we demonstrated that there were both bull and sorting effects that resulted in differential embryo development in sexed IVF and that the bull effect had more influence than the sorting process. The bull effect for IVF is believed due to the difference of sperm

Table 3. The effect of sorting pressure and the time between semen collection and sorting on subsequent development of sexed in vitro fertilized (IVF) embryos

\begin{tabular}{lllllll}
\hline & \multirow{2}{*}{$\begin{array}{l}\text { Sorting } \\
\text { pressure } \\
\text { Treatment }\end{array}$} & $\begin{array}{l}\text { Time of } \\
\text { (psi) }\end{array}$ & $\begin{array}{l}\text { sorting } \\
(\mathrm{h})^{2}\end{array}$ & $\begin{array}{l}\text { Oocytes } \\
(\mathrm{n})\end{array}$ & & \multicolumn{2}{c}{ Embryo development (mean \pm SEM) } \\
\cline { 5 - 7 } & 40 & 9 & 1191 & $63.3 \pm 6.6^{\mathrm{a}}$ & $29.7 \pm 1.3^{\mathrm{a}}$ & $23.5 \pm 0.9^{\mathrm{a}}$ \\
\hline 1 & 40 & 14 & 1207 & $69.4 \pm 7.5^{\mathrm{a}}$ & $28.1 \pm 2.2^{\mathrm{a}}$ & $25.3 \pm 3.0^{\mathrm{a}}$ \\
2 & 50 & 9 & 1433 & $51.9 \pm 9.7^{\mathrm{a}}$ & $30.3 \pm 5.5^{\mathrm{a}}$ & $20.7 \pm 2.5^{\mathrm{a}}$ \\
3 & 50 & 14 & 1288 & $60.8 \pm 1.7^{\mathrm{a}}$ & $36.5 \pm 6.4^{\mathrm{a}}$ & $23.7 \pm 2.1^{\mathrm{a}}$ \\
\hline
\end{tabular}

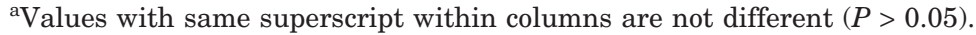

${ }^{1}$ There were 3 replicates per treatment. Embryo development to cleavage ( 2 to 8 cell), morula, and blastocyst was evaluated on d 2, 5, and 7 post-IVF, respectively, according to the standard of the International Embryo Transfer Society.

${ }^{2}$ Time of sorting indicates the extended period $(\mathrm{h})$ between semen ejaculation and sperm sorting. 
Table 4. In vitro and in vivo developmental competence of sex-sorted in vitro fertilized (IVF) embryos

\begin{tabular}{|c|c|c|c|c|c|c|c|c|}
\hline \multirow[b]{2}{*}{$\begin{array}{l}\text { Embryo } \\
\text { type }^{1}\end{array}$} & \multirow[b]{2}{*}{$\begin{array}{l}\text { Embryos } \\
(\mathrm{n})\end{array}$} & \multicolumn{5}{|c|}{$\begin{array}{l}\text { Postwarming survivability and development of vitrified } \\
\text { embryos, } \% \text { (mean } \pm \text { SEM) }\end{array}$} & \multicolumn{2}{|c|}{$\begin{array}{l}\text { Embryo transfer results } \\
\quad(\text { mean } \pm \text { SEM })\end{array}$} \\
\hline & & $2 \mathrm{~h}$ & $24 \mathrm{~h}$ & $72 \mathrm{~h}$ & $\begin{array}{l}\text { Hatched } \\
\text { at } 72 \mathrm{~h}\end{array}$ & Cell count ${ }^{2}$ & $\begin{array}{l}\text { No. of } \\
\text { recipients }{ }^{3}\end{array}$ & Pregnancies, ${ }^{4} \%$ \\
\hline Sorted & 164 & $96.4 \pm 1.4^{\mathrm{a}}$ & $96.3 \pm 1.5^{\mathrm{a}}$ & $96.3 \pm 1.5^{\mathrm{a}}$ & $84.4 \pm 3.0^{\mathrm{a}}$ & $538 \pm 35^{\mathrm{a}}$ & 3,627 & $40.9 \pm 3.6^{\mathrm{a}}$ \\
\hline Nonsorted & 149 & $93.1 \pm 1.5^{\mathrm{a}}$ & $91.8 \pm 1.5^{\mathrm{a}}$ & $91.8 \pm 1.9^{\mathrm{a}}$ & $80.6 \pm 3.7^{\mathrm{a}}$ & $515 \pm 33^{\mathrm{a}}$ & 481 & $41.9 \pm 3.0^{\mathrm{a}}$ \\
\hline In vivo & NA & & & & & & 192 & $53.1 \pm 0.5^{\mathrm{a}}$ \\
\hline
\end{tabular}

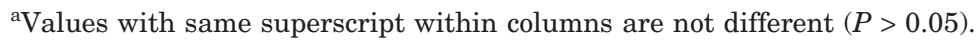

${ }^{1}$ Sorted $=$ sexed IVF blastocysts fertilized with sorted X-bearing sperm; Nonsorted $=$ nonsexed IVF blastocysts fertilized with conventional nonsexed semen; In vivo = in vivo embryos cryopreserved by conventional programmed slow freezing protocol; NA, In vivo-derived embryos were not thawed for the survivability test.

${ }^{2}$ Twenty-five hatched IVF blastocysts from sorted and nonsorted vitrification groups were applied for nuclear evaluation by fluorescent microscopy.

${ }^{3}$ Sexed or nonsexed embryos were vitrified on d 7 after IVF. After thawing, only a single embryo derived from either IVF (sexed or nonsexed) or in vivo flushing was transferred nonsurgically into each synchronized recipient.

${ }^{4}$ Pregnancy of recipients was examined by palpation per rectum on $\mathrm{d} 70$ posttransfer.

capacitation for individual bulls during the process of fertilization (Parrish et al., 1986). The 9 bulls used were selected for their genetic merits and availability, but not to their in vitro fertility. After sorting, sperm from bulls A, B, and D (3/4) maintained similar in vitro fertility to sperm that were not sorted; however, the fertility for bull $\mathrm{C}$ was significantly decreased. These results indicated that the sorting process affected the in vitro fertility of sorted sperm in a bull specific manner, but it was not a significant factor for all bulls. The bull effect of the sorting process on the in vitro fertility may have reflected recent improvements in sperm sorting technology. In vitro fertilization with conventional sperm from bull $\mathrm{C}$ resulted in a significant difference (0.7 to $20.7 \%$, Table 1) in blastocyst development. Likewise, IVF with sorted sperm of 9 bulls (A to I) resulted in significant variation in blastocyst development (Figure 1). Embryos fertilized by X-bearing sperm from bulls A, E, and F (3/9) had significantly higher blastocyst rates than those from 6 other bulls, and would satisfy the need for a large-scale embryo production. Further research is needed to optimize the use of sexed IVF by using different sperm concentration, as suggested by Lu and Seidel (2004).

Our results with different doses of sperm suggested that the sperm concentration $\left(0.15\right.$ vs. $\left.0.3 \times 10^{6} / \mathrm{mL}\right)$ is more critical than the sperm/oocyte ratio $(300,600$, or 1,200 sperm/oocyte), and is dependent upon droplet size (Table 2) in supporting high cleavage and blastocyst rates. The minimum number of X-bearing sperm required to fertilize an oocyte could be reduced by half, from 1,200 to 600 , while maintaining a similar and satisfactory blastocyst rate at a sperm concentration of $0.3 \times$ $10^{6} / \mathrm{mL}$ if droplet size was 50 vs. $100 \mu \mathrm{L}$. This is a $>8-$ fold reduction of our routine IVF with nonsexed sperm (5,000 sperm/egg; Yang et al., 1993). Twenty thousand sorted sperm per oocyte were used in the pioneering work of Cran et al. (1995) and a minimum of 1,500 sexed sperm was used to fertilize $1 \mathrm{egg}$ (Lu and Seidel, 2004).

Sorting pressure (275.8 or $344.75 \mathrm{kPa}$ ) and time until sorting (9 or $14 \mathrm{~h}$ postejaculation) did not affect the in
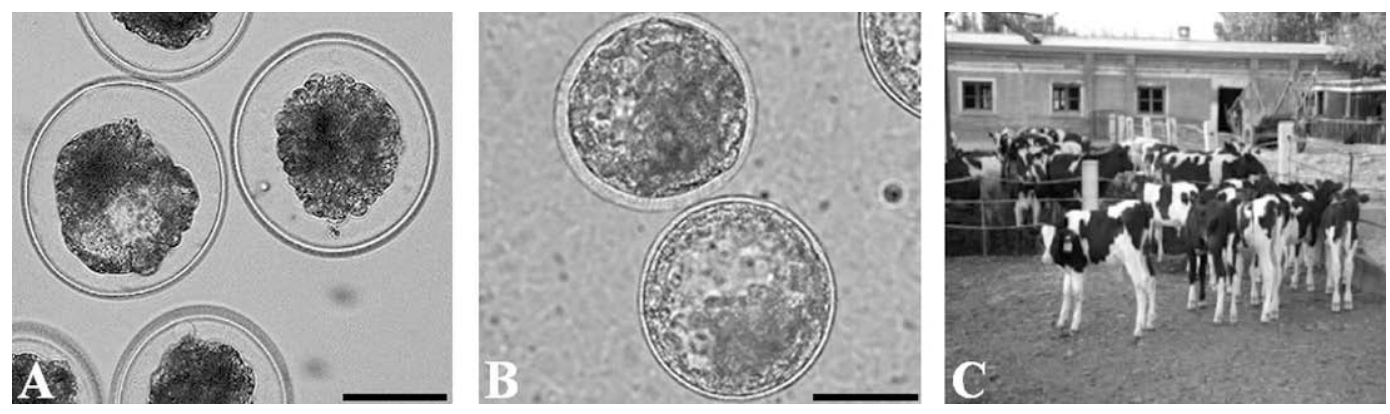

Figure 2. Development of bovine sex-preselected embryos derived by in vitro fertilization with sorted X-bearing sperm and vitrification. Vitrified embryos showed a dramatic shrinkage of embryo mass shortly postwarming (A); but fully reexpanded to the expanding stage before cryopreservation (B) with more than 96\% survival and recovery rate after $2 \mathrm{~h}$ postwarming. Female Holstein calves were born following embryo transfer of vitrified, sex-preselected embryos (C). Bar represents $80 \mu \mathrm{m}$ in panels A and B. 


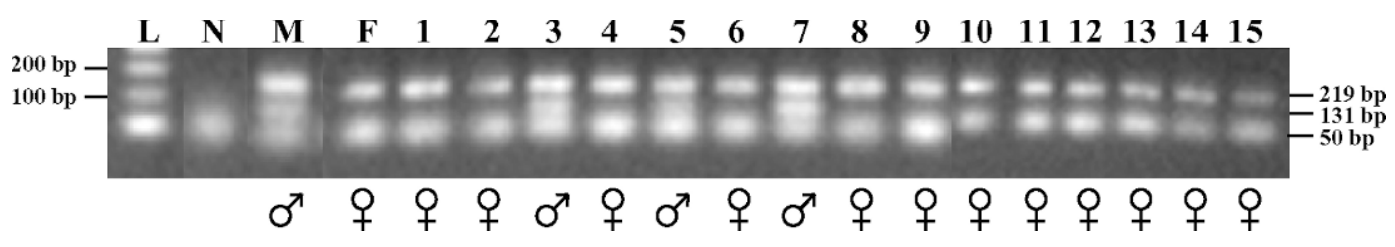

Figure 3. Representative gel of PCR sexing of bovine blastocysts fertilized in vitro by sorted X-bearing sperm. Amplification of bovinespecific autosome and Y-chromosome DNA fragments was performed by a multiplex PCR as described in the Materials and Methods. A PCR product of 219 and $131 \mathrm{bp}$ indicated a bovine autosome DNA fragment and specific Y-chromosome DNA amplicon, respectively. The lower 50-bp band = PCR primer dimers; $\mathrm{L}=100$-bp DNA ladder; $\mathrm{N}=$ negative control; $\mathrm{M}=$ positive male control; $\mathrm{F}=$ positive female control. One band (219 bp) indicated a female embryo, and 2 bands (219 and $131 \mathrm{bp}$ ), a male embryo. Lanes $1,2,4,6$, and 8 to 15 were identified as positive for females ( + ); and lanes 3,5 , and 7, for males ( 0 ). In our PCR experiment, the female ratio was 95.9\% ( $\mathrm{n}=148$ ) in sexed IVF embryos and $54.2 \%$ in nonsexed IVF controls $(n=118)$.

vitro fertility (Table 3). Increasing the sorting pressure could result in increased sorting speeds and throughput. A longer period before sorting makes it possible to acquire fresh ejaculates from top-ranking sires at remote locations and transport them overnight to the sorting facility. This is of practical importance because sires currently need to be located in close proximity to sorting facility, and because there are only very few sorting facilities available.

The LNSV method developed by our group (Du et al., 2004, 2006) resulted in satisfactory performance with nonsexed IVF bovine embryos (Du et al., 2004), in vivo embryos (Lonergan et al., 2005), and cloned embryos (Du et al., 2006). In the present study, 96.3\% survival and $84.4 \%$ hatching rates were achieved from LNSV of Holstein embryos produced by sorted X-bearing sperm in vitro (Table 4 ). These results were comparable to their nonsexed IVF counterparts. In addition, the pregnancy/ implantation rate of $40.9 \%$ was not different from embryos of nonsexed IVF (41.9\%) or in vivo (53.1\%) controls. This was higher than rates reported previously for nonsexed fresh IVF (Al-Katanani et al., 2002), sexed fresh IVF (Wilson et al., 2005), nonsexed frozen IVF (Al-Katanani et al., 2002), and sexed frozen IVF embryos (Cran et al., 1993, 1995). These results demonstrated that the LNSV vitrification method can cryopreserve sexed IVF embryos with minimal damage to the cells, and that high in vitro and in vivo developmental competence can be attained postthaw.

We report the birth of live calves from vitrified embryos produced from sex-sorted sperm IVF embryos. The ratio of female calves was $96.5 \%$, consistent with our in vitro PCR data (95.9\%), and interestingly, higher than the technical specifications provided by XY Inc. (90 \pm $3 \%$; Schenk et al., 1999). To our knowledge, this is the first report of live calf production from IVF embryos fertilized by sorted X-bearing sperm and cryopreserved by vitrification. The abortion rate (5.5\%) from sexed IVF embryos was not different from that of nonsexed IVF and in vivo embryos. The abortion rate of the sexed IVF embryos was higher than the reported abortion rate of in vivo embryos (3.15\%; King et al., 1985), but is much lower than that reported for nonsexed in vitro embryos (13.1\%; Hasler, 2000), and is comparable to that achieved by AI with sexed semen (4.5\%; Tubman et al., 2004). Less than $1 \%(2 / 458)$ of the calves had physical defects and all others appeared normal. The sperm-sorting processes did not appear to adversely affect the implantation efficiency of the embryos; neither did it seem to cause genetic damage to sorted female embryos. This is consistent with results from other groups in which calves produced by AI with sorted sperm were normal (Tubman et al., 2004).

\section{CONCLUSIONS}

In summary, the present study demonstrates an efficient system for the large-scale production, cryopreservation, and transfer of sexed IVF embryos produced by sorted sperm. Both bulls and sorting influenced IVF with sexed sperm. One-third of bulls tested were suitable for sexed IVF embryo production. A minimal number of 600 sorted sperm in $50 \mu \mathrm{L}$ was sufficient to fertilize an oocyte in vitro, yielding satisfactory developmental rates. Neither increased sorting pressure nor extending the period between collecting the ejaculate and sorting the sperm affected sperm quality and fertility. Over 33\% blastocyst development rates from sexed IVF embryos as well as high postwarming survivability of vitrified embryos were achieved. High pregnancy rates $(40.9 \%)$ were established in a large embryo transfer trial. This, combined with the low abortion rates, predictable sex of offspring, and the birth of healthy calves, demonstrated that a system of sperm sexing, in vitro embryo production, vitrification, and embryo transfer is a feasible and efficient method to produce livestock of the desired sex for the purpose of herd expansion and fast genetic replacement.

\section{ACKNOWLEDGMENTS}

We sincerely appreciate Shie Jiang, Yuqing Zhang, LiYing Sung, Colleen Shaffer, Alicia Shefler, Terra Kilmer, 
and Fei Xue for technical support and assistance, Shiying Li for administrative support; and Shiyuan Ma, Genhai Yang, Shaowang Geng, Yucai Lv, Weili Xin, and Xiangjun Yang for performing embryo transfer trials in Chinese farms. George E. Seidel and Robert H. Foote provided valuable discussion and comments in the preparation of this manuscript. This study was supported by the Small Business Innovation Research program of the USDA Cooperative State Research, Education, and Extension Service (CSREES), Grant Number 2005-00178 to Fuliang Du, and Yankee Ingenuity Competition from Connecticut Innovation, Inc., to Xiangzhong Yang.

\section{REFERENCES}

Al-Katanani, Y. M., M. Drost, R. L. Monson, J. J. Rutledge, C. E. Krininger, J. Block, W. W. Thatcher, and P. J. Hansen. 2002. Pregnancy rates following timed embryo transfer with fresh or vitrified in vitro produced embryos in lactating dairy cows under heat stress conditions. Theriogenology 58:171-182.

Beyhan, Z., L. A. Johnson, and N. L. First. 1999. Sexual dimorphism in IVM-IVF bovine embryos produced from $\mathrm{X}$ and $\mathrm{Y}$ chromosomebearing spermatozoa sorted by high speed flow cytometry. Theriogenology 52:35-48.

Brackett, B. G., D. Bousquet, M. L. Boice, W. J. Donawick, J. F. Evans, and M. A. Dressel. 1982. Normal development following in vitro fertilization in the cow. Biol. Reprod. 27:147-158.

Cran, D. G., L. A. Johnson, N. G. Miller, D. Cochrane, and C. Polge. 1993. Production of bovine calves following separation of $X$ - and Y-chromosome bearing sperm and in vitro fertilisation. Vet. Rec. 132:40-41.

Cran, D. G., L. A. Johnson, and C. Polge. 1995. Sex preselection in cattle: A field trial. Vet. Rec. 136:495-496.

Du, F., A. Dinnyés, L. Y. Sung, J. Xu, S. Jiang, X. C. Tian, and X. Yang. 2004. Embryo transfer of vitrified IVF embryos in cattle: Pregnancy comparison after single and double transfer. Reprod. Fertil. Dev. 16:209. (Abstr.)

Du, F., P. C. Shen, J. Xu, L. Y. Sung, B. S. Jeong, T. Lucky Nedambale, J. Riesen, X. Cindy Tian, W. T. Cheng, S. N. Lee, and X. Yang. 2006. The cell agglutination agent, phytohemagglutinin-L, improves the efficiency of somatic nuclear transfer cloning in cattle (Bos taurus). Theriogenology 65:642-657.

Hasler, J. F. 2000. In-vitro production of cattle embryos: Problems with pregnancies and parturition. Hum. Reprod. 15(Suppl. 5):47-58.

Johnson, L. A. 2000. Sexing mammalian sperm for production of offspring: The state-of-the-art. Anim. Reprod. Sci. 60-61:93-107.

King, K. K., G. E. Seidel, and R. P. Elsden. 1985. Bovine embryo transfer pregnancies. I. Abortion rates and characteristics of calves. J. Anim. Sci. 61:747-757.

Lonergan, P., A. C. O. Evans, E. Boland, D. Rizos, L. Y. Sung, F. Du, S. Chaubal, S. Fair, E. Scraggs, P. Duffy, J. Xu, X. Yang, and X. C. Tian. 2005. Pregnancy and fetal characteristics after transfer of vitrified in vivo and cloned bovine embryos. Reprod. Fertil. Dev. 17:173. (Abstr.)

Lu, K. H., D. G. Cran, and G. E. Seidel. 1999. In vitro fertilization with flow-cytometrically sorted bovine sperm. Theriogenology 52:1393-1405.

Lu, K. H., and G. E. Seidel. 2004. Effects of heparin and sperm concentration on cleavage and blastocyst development rates of bovine oocytes inseminated with flow cytometrically sorted sperm. Theriogenology 62:819-830.

Nadir, S., R. G. Saacke, J. Bame, J. Mullins, and S. Degelos. 1993. Effect of freezing semen and dosage of sperm on number of accessory sperm, fertility, and embryo quality in artificially inseminated cattle. J. Anim. Sci. 71:199-204.

Parrish, J. J., J. L. Susko-Parrish, M. L. Leibfried-Rutledge, E. S. Crister, and W. H. Eyestone. 1986. Bovine in vitro fertilization with frozen-thawed semen. Theriogenology 25:591-600.

Robertson, I., and R. E. Nelson. 1998. Certification and identification of the embryo. Pages 103-134 in Manual of the International Embryo Transfer Society. 3rd ed. S. M. Seidel, ed. International Embryo Transfer Society, Savoy, IL.

Rosenkrans, C. F., Jr., G. Q. Zeng, G. T. McNamara, P. K. Schoff, and N. L. First. 1993. Development of bovine embryos in vitro as affected by energy substrates. Biol. Reprod. 49:459-462.

Schenk, J. L., T. K. Suh, D. G. Cran, and G. E. Seidel. 1999. Cryopreservation of flow-sorted bovine spermatozoa. Theriogenology 52:1375-1391.

Seidel, G. E. 1999. Sexing mammalian spermatozoa and embryosstate of the art. J. Reprod. Fertil. Suppl. 54:477-487.

Sommerfeld, V., and H. Niemann. 1999. Cryopreservation of bovine in vitro produced embryos using ethylene glycol in controlled freezing or vitrification. Cryobiology 38:95-105.

Tominaga, K., and Y. Hamada. 2004. Efficient production of sex-identified and cryosurvived bovine in-vitro produced blastocysts. Theriogenology 61:1181-1191.

Tubman, L. M., Z. Brink, T. K. Suh, and G. E. Seidel. 2004. Characteristics of calves produced with sperm sexed by flow cytometry/cell sorting. J. Anim. Sci. 82:1029-1036.

van Munster, E. B., J. Stap, R. A. Hoebe, G. J. te Meerman, and J. A. Aten. 1999. Difference in sperm head volume as a theoretical basis for sorting X- and Y-bearing spermatozoa: Potentials and limitations. Theriogenology 52:1281-1293.

Wheeler, M. B., J. J. Rutledge, A. Fischer-Brown, T. Vanetten, S. Malusky, and D. J. Beebe. 2006. Application of sexed semen technology to in vitro embryo production in cattle. Theriogenology 65:219-227.

Wilson, R. D., P. M. Fricke, M. L. Leibfried-Rutledge, J. J. Rutledge, C. M. Penfield, and K. A. Weigel. 2006. In vitro production of bovine embryos using sex-sorted sperm. Theriogenology 65:1007-1015.

Wilson, R. D., K. A. Weigel, P. M. Fricke, J. J. Rutledge, M. L. LeibfriedRutledge, D. L. Matthews, and V. R. Schutzkus. 2005. In vitro production of Holstein embryos using sex-sorted sperm and oocytes from selected cull cows. J. Dairy Sci. 88:776-782.

Yang, X., S. Jiang, and R. H. Foote. 1993. Bovine oocyte development following different oocyte maturation and sperm capacitation procedures. Mol. Reprod. Dev. 34:94-100.

Zhang, M., K. H. Lu, and G. E. Seidel. 2003. Development of bovine embryos after in vitro fertilization of oocytes with flow cytometrically sorted, stained and unsorted sperm from different bulls. Theriogenology 60:1657-1663. 